\title{
PENDIDIKAN PROFESI GURU DALAM PANDANGAN MAHASISWA
}

\author{
Destri Ratna Ma'rifah ${ }^{1}$, Purwanti Pratiwi Purbosari² \\ ${ }^{1,2}$ Universitas Ahmad Dahlan, Yogyakarta, 55191
}

Email Korespondensi: destrirm@pbio.uad.ac.id

Diajukan: 1 January 2020; Diterima: 2 February 2020; Diterbitkan: 30 April 2020

\begin{abstract}
Abstrak: Program kebijakan pemerintah terkait dengan profesionalitas guru saat ini tengah digalakkan melalui program Pendidikan Profesi Guru (PPG). Dalam kurun waktu pelaksanaan PPG tersebut, belum diketahui secara jelas terkait pandangan mahasiswa yang saat ini berkuliah di program studi kependidikan, terutama pendidikan biologi FKIP UAD, terkait program PPG. Pengetahuan akan persepsi mahasiswa diharapkan dapat menjadi salah satu informasi yang berguna bagi keselarasan antara program studi kependidikan dengan program PPG. Penelitian ini bertujuan untuk mengetahui pandangan mahasiswa angkatan 2015 yang merupakan mahasiswa semester VIII) Program Studi Pendidikan Biologi FKIP UAD terkait dengan program PPG. Penelitian ini merupakan penelitian deskriptif kualitatif. Data yang diperoleh dalam penelitian ini adalah data kualitatif. Data yang diperoleh dianalisis secara deskriptif menggunakan teknik reduksi data, penyajian data dan penarikan simpulan. Data dikumpulkan melalui angket terbuka dan wawancara kepada responden. Responden dalam penelitian ini sebanyak 42 mahasiswa angkatan 2015 Program Studi Pendidikan Biologi FKIP UAD yang dipilih secara acak. Dari penelitian ini diketahui bahwa 100\% mahasiswa Prodi Pendidikan Biologi angkatan 2015 mengetahui adanya program PPG. 93\% mahasiswa mengetahui informasi tentang PPG saat mereka duduk di bangku kuliah, sedangkan $7 \%$ mengetahui saat masih di bangku SMA. Mahasiswa mengetahui adanya program PPG ini dari beberapa sumber. Pengetahuan mahasiswa angkatan 2015 terkait sasaran, manfaat, dan pelaksanaan program PPG bervariasi. $71,43 \%$ mahasiswa mengaku tertarik untuk mengikuti program PPG, sedangkan 28,57\% tidak tertarik. Mahasiswa yang tidak berminat untuk mengikuti PPG menyampaikan alasan bahwa mereka lebih memilih untuk langsung melanjutkan ke jenjang S2 atau langsung bekerja. Alasan lain adalah lantaraan merasa belum diwajibkan untuk mengikuti program PPG, serta adapula yang dikarenakan belum ingin menjadi guru. Terkait saran mahasiswa terhadap pelaksanaan program PPG cukup bervariasi.
\end{abstract}

Kata Kunci: persepsi, pendidikan profesi guru, mahasiswa

Abstract: Government policy programs related to teacher professionalism are currently being promoted through the Teacher Professional Education (PPG) program. During the PPG implementation period, it was not clear what the views of students currently studying in educational study programs, especially biology education at FKIP $U A D$, related to the PPG program were. Knowledge of student perceptions is expected to be one of the useful information for alignment between educational study programs and PPG programs. This study aims to determine the views of 2015 students who are semester VIII students of the Biology Education Study Program, FKIP UAD related to the PPG program. This research is a qualitative descriptive study. The data obtained in this study is qualitative data. The data obtained were analyzed descriptively using data reduction techniques, data presentation and drawing conclusions. Data were collected through open questionnaires and interviews with respondents. Respondents in this study were 42 students of the 2015 Biology Education Study Program, FKIP UAD who were randomly selected. From this research, it is known that 100\% of students of the 2015 Biology Education Study Program are aware of the PPG program. 93\% of students know information about PPG when they are in college, while 7\% know when they are still in high school. Students know about this PPG program from several sources. The knowledge of the 2015 students regarding the objectives, benefits, and implementation of the PPG program varies. $71.43 \%$ of students claimed to be interested in joining the PPG program, while $28.57 \%$ were not. Students who are not interested in participating in PPG convey the reason that they prefer to directly continue to the Masters level or go straight to work. Another reason is because they feel they are not obliged to join the PPG program, and some are because they don't want to become a teacher. Regarding student suggestions for the implementation of the PPG program, it is quite varied.

Keywords: perception, teacher professional education, students 


\section{Pendahuluan}

Profesionalitas sebagai seorang pengajar saat ini lebih diperhatikan oleh pemerintah. Perkembangan jaman dan era globalisasi yang menuntut persaingan ketat adalah salah satu faktor yang mendesak perbaikan sistem pendidikan, termasuk peningkatan profesionalitas guru (Yusutria, 2017). Perhatian pemerintah untuk meningkatkan profesionalitas guru salah satunya dituangkan melalui pelaksanaan program Pendidikan Profesi Guru (PPG) guna meningkatkan kemampuan dan kompetensi guru. Program tersebut selain menyasar pada peningkatan kompetensi guru-guru yang telah mengajar di sekolah, juga menyasar calon guru agar lebih siap dan profesional saat mereka menjadi guru nantinya.

Berbagai versi PPG telah diadakan oleh pemerintah, diantaranya PPG pra-jabatan, PPG dalam-jabatan, PPG mandiri, PPG subsidi. Selain itu, ada pula versi PPG khusus untuk peserta Program Sarjana Mendidik di daerah Terluar, Terdepan dan Tertinggal (SM3T), yaitu PPG SM3T (Yustina \& Wansyafii, 2016). PPG sebagai program yang baru, diharapkan dapat menjadi program lanjutan yang memantapkan pengetahuan dan keterampilan yang telah diperoleh oleh seorang lulusan sarjana. Program pembelajaran dan pengalaman yang diberikan dalam PPG diharapkan selaras dan tidak tumpang tindih dengan program pada strata 1 (S1) (Ningrum, 2012). Akan tetapi informasi tentang keselarasan ini bisa jadi belum banyak diketahui oleh mahasiswa yang masih menempuh studi S1, termasuk mahasiswa pada program studi kependidikan. Begitu pula dengan tujuan diselenggarakannya PPG dan kurikulum yang diterapkan pada program PPG. Informasi ini seharusnya bisa menjadi daya tarik tersendiri bagi lulusan program S1 untuk mengambil program PPG.

Program PPG selain melibatkan sarjana lulusan program studi kependidikan sebagai calon peserta, juga memberi kesempatan kepada lulusan non-kependidikan untuk ikut mendaftar sehingga memiliki sertifikat pendidik profesional (Mendikbud, 2013). Hal ini selain memberikan kesempatan bagi lulusan non kependidikan yang memiliki minat dan bakat untuk menjadi guru, bisa juga menimbulkan dampak lain yaitu akan mengarah pada persaingan yang lebih ketat bagi mahasiswa yang menginginkan menjadi guru profesional karena baik lulusan kependidikan maupun non-kependidikan memiliki hak yang sama. Hal tersebut menjadi salah satu bagian yang menarik untuk diketahui, yaitu terkait pandangan mahasiswa jurusan kependidikan terhadap kebijakan program ini. Selain itu, waktu tempuh program, universitas penyelenggara, dan kegunaan dari kepemilikian sertifikat pendidik profesional seharusnya juga menjadi informasi yang penting bagi calon pendaftar PPG. Akan tetapi belum diketahui pandangan mahasiswa, terutama mahasiswa jurusan kependidikan, terkait hal-hal yang melekat pada program PPG.

Program Studi Pendidikan Biologi FKIP UAD adalah salah satu LPTK yang menghasilkan calon-calon guru biologi. Terdapat satu angkatan mahasiswa pada Program Studi Pendidikan Biologi FKIP UAD tersebut yang akan segera lulus dan dapat menentukan pilihan mereka untuk mengikuti program PPG. Oleh karena itu, pengetahuan akan persepsi mahasiswa terkait program PPG beserta ketertarikannya untuk mengikuti program PPG perlu diungkapkan melalui kegiatan penelitian ini.

\section{Metode Penelitian}

Subjek dalam penelitian ini adalah mahasiswa Program Studi Pendidikan Biologi FKIP UAD angkatan tahun 2015 (Semester VIII). Populasinya terdiri dari 120 mahasiswa. Pada angkatan ini, menggunakan purposive random sampling diambil sebanyak 42mahasiswa sebagai sampel dari penelitian. Pengumpulan data dilakukan dengan teknik non-tes. Teknik non-tes dilakukan dengan menggunakan angket dan wawacara. Guna memperoleh data-data tersebut, digunakan dua jenis instrumen, yaitu angket terbuka dan pedoman wawancara. Kedua instrumen ini digunakan sebagai upaya untuk mengungkap data lebih lengkap. Selain itu juga menjadi bentuk dari triangulasi metode dalam pengumpulan data.

Data yang diperoleh berupa data kualitatif yang didapat dari jawaban angket 
terbuka dan hasil wawancara mendalam kepada mahasiswa. Data kualitatif berupa jawaban kuesioner mahasiswa direduksi guna mempermudah dalam pembacaannya berdasarkan faktor utama yang hendak dibahas. Data kuesioner disajikan dalam bentuk diagram. Data hasil wawancara digunakan untuk memverifikasi jawaban dari mahasiswa dalam angket terbuka dan melengkapi data yang sudah terkumpul sebelumnya. Tahap selanjutnya dilakukan penyajian. Pada tahap akhir dalam analisis data, dilakukan penarikan simpulan sementara berdasarkan keseluruhan data yang diperoleh. Pada setiap tahapannya dilakukan diskusi bersama dengan ahli serta sesama peneliti.

\section{Hasil Penelitian dan Pembahasan}

Penelitian ini dilakukan pada bulan Maret s/d Agustus 2019 di Kampus 4 Universitas Ahmad Dahlan.Berdasarkan penelitian yang dilakukan, $100 \%$ responden mengetahui adanya program Pendidikan Profesi Guru (PPG) yang diselenggarakan oleh pemerintah. Pada angket yang disebarkan $100 \%$ dari responden manyatakan mengetahui tentang PPG. Akan tetapi, ketika dilakukan wawancara terungkap informasi yang kurang tepat dari satu responden terkait kepanjangan dari istilah PPG. Meskipun responden yang bersangkutan salah dalam menyebutkan kepanjangan dari PPG, tetapi yang bersangkutan memahami tentang apa itu PPG. Oleh karena itu, dapat dikatakan jika seluruh responden mengetahui tentang PPG.

Pengetahuan yang dimiliki oleh responden tidak terlepas dari pengalaman sebelumnya. Pengalaman yang diperoleh responden sejak sebelum kuliah maupun saat kuliah perlu untuk diketahui lebih lanjut. Pada salah satu butir angket terdapat pertanyaan tentang hal ini yang kemudian dilanjutkan dengan wawancara.

Berdasarkan data yang didapat dari angket, sebanyak $93 \%$ responden baru mengetahui adanya program PPG saat sudah menjadi mahasiswa di Prodi Pendidikan Biologi FKIP UAD. Kebanyakan menuliskan bahwa pengetahuan tentang PPG diperoleh ketika menempuh kuliah semester 2. Sementara itu, $7 \%$ responden sudah mengetahui adanya program PPG sejak masih duduk di Sekolah Menengah Atas (SMA). Pengetahuan yang diperoleh mahasiswa ketika semester 2 berkaitan dengan adanya mata kuliah terkait keprofesian guru, sehingga responden mendapatkan informasi dari kegiatan perkuliahan yang dilakukan. Gambar 1 menunjukkan persentase pengetahuan responden ketika pertama kali mendapatkan informasi PPG.

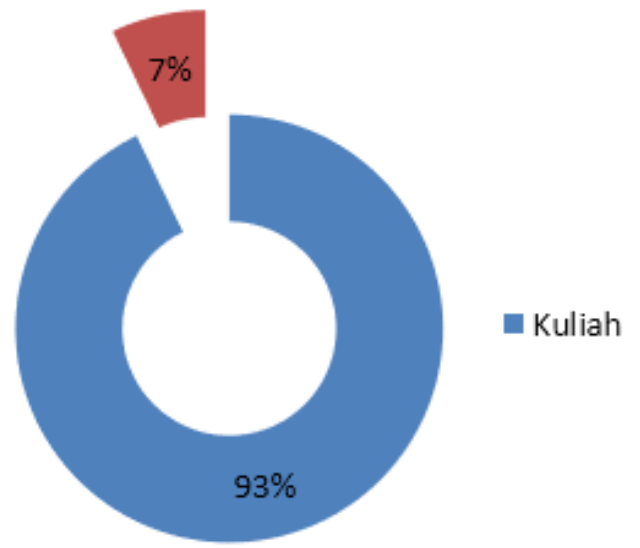

Gambar 1. persentase pengetahuan responden terkait waktu pertama kali mendapatkan informasi PPG

Terdapat berbagai sumber informasi pertama bagi responden terkait pengetahuan mereka tentang PPG. Sumber informasi pertama bagi responden tersebut antara lain dari guru SMA, orangtua/saudara yang menjadi guru, dosen, teman, serta kakak kos yang menjadi guru. Ditemukan fakta yang menarik terkait dengan hal ini, yaitu pengetahuan yang dimiliki oleh responden ada yang diperoleh ketika melakukan kegiatan magang di sekolah. Kegiatan magang ke sekolah memberikan tambahan pengetahuan bagi responden terkait dengan PPG dari pesertanya langsung yang sedang praktek di sekolah.

Pengetahuan responden terkait sasaran dan manfaat program PPG bervariasi. Dari segi sasaran program PPG, $90,5 \%$ responden menjawab dengan tepat yaitu program PPG tidak hanya bagi lulusan kependidikan saja, melainkan bisa juga diikuti oleh lulusan nonkependidikam. Sebanyak $9,5 \%$ responden memberikan jawaban yang kurang tepat. Responden yang menjawab kurang tepat ini mengira bahwa hanya lulusan kepedidikan saja yang bisa mengikuti program PPG. Bahkan adapula yang menyampaikan bahwa sasaran 
program PPG adalah lulusan S2. Gambar 2 menyajikan persentase pengetahuan responden tentang sasaran PPG.

Menurut seluruh responden, program PPG yang diadakan oleh pemerintah jelas memiliki manfaat. Manfaat yang diketahui responden dari program PPG adalah program ini dapat meningkatkan kompetensi/kualitas guru, bisa menjadi jalan bagi guru untuk mendapatkan sertifikat pendidik, memudahkan dan menjadi syarat Calon Pegawai Negeri Sipil (CPNS), meningkatkan perekonomian guru, membuat guru memperoleh akta IV, serta pembelajaran di kelas/sekolah akan menjadi lebih baik setelah guru mengikuti PPG. Beberapa manfaat yang disampaikan oleh responden sejalan dengan analisis yang dilakukan oleh Disas (2017) bahwa manfaat dari program PPG antara lain menciptakan guru yang profesional, meningkatkan kesejahteraan guru, dan semua sarjana (termasuk sarjana nonkependidikan) bisa menjadi peserta PPG

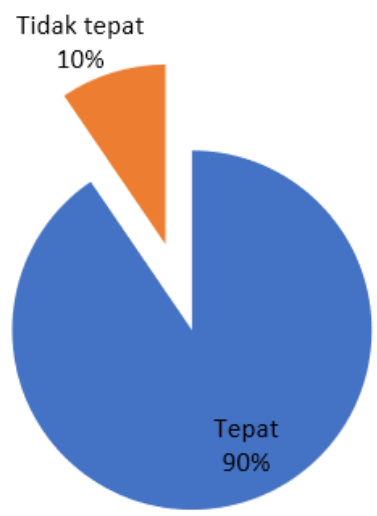

Gambar 2. Ketepatan jawaban responden terkait sasaran PPG

Terkait pelaksanaan program PPG, pengetahuan responden bervariasi. Terkait waktu pelaksanaan, sebagian besar mahasiswa mengetahui bahwa PPG dilaksanakan selama 1 tahun (2 semester) dengan disertai praktik mengajar di sekolah. Akan tetapi, ada 1 responden yang salah mendapatkan informasi bahwa PPG dilaksanakan selama 2 tahun.

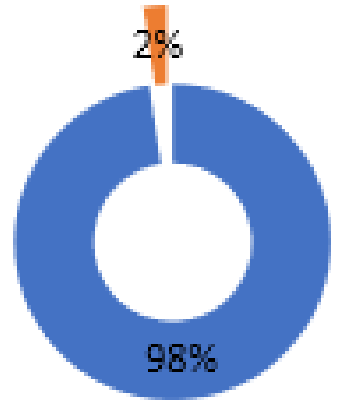

2 semester

ㅁ 2 tahun

Gambar 3. Persentase pengetahuan responden tentang waktu pelaksanaan PPG

Berbagai manfaat yang dipersepsikan oleh responden perlu diketahui juga terkait kekukarangnnya. Beberapa kekurangan PPG dari sudut pandang dan pengetahuan responden antara lain kampus penyelenggaranya masih sedikit (hanya di universitas tertentu), informasi terkait program PPG kurang jelas, biaya mengikuti program PPG mahal, waktu yang ditempuh untuk menyelesaikan program PPG lumayan lama, sulit mendapat kesempatan mengikuti program PPG karena adanya seleksi yang ketat, serta program PPG dibuka untuk semua jurusan bukan hanya untuk mahasiswa lulusan kependidikan saja.

Terdapat beberapa poin dari kekurangan PPG hasil data dari angket sehingga wawancara sangat membantu dalam pengungkapan informasi sebenarnya. Pada poin kekurangan kampus penyelenggara masih sedikit, karena hanya ada beberapa universitas tertentu yang ditunjuk pemerintah menjadi penyelenggara PPG. Kekurangan terkait dengan lama waktu PPG ternyata dikarenakan persepsi responden bahwa setelah menempuh kuliah selama 4 tahun (minimal) di jurusan kependidikan masih harus menempuh PPG selama 1 tahun agar dapat mendapatkan sertifikat pendidik.Terkait kekurangan ini, pada penelitian yang dilakukan oleholeh Sumaryono \& Ismandiri (2015) terhadap mahasiswa kependidikan pada Fakultas Ekonomi didapatkan hasil bahwa terdapat $31,37 \%$ mahasiswa tidak setuju dengan adanya program PPG lantaran mereka menganggap bahwa PPG kurang efektif dari segi manfaat, pengingkaran kualitas, peningkatan profesionalitas, keperluan, dan finansial calon guru.

Terkait pandangan responden dalam penelitian ini yang beranggapan bahwa salah 
satu kekurangan PPG adalah diperbolehkannya sarjana non-kependidikan untuk mengikuti program PPG dan menyandang guru profesional sejalan dengan pendapat yang disampaikan oleh Margi \& Atmaja (2013). Dalam kajian tersebut disampaikan bahwa diperbolehkannya sajana non-kependidikan mengikuti program PPG sudah memiliki landasan filosofis, yuridis, historis, dan konseptual. Akan tetapi hal tersebut akan memperluas ruang kompetisi dalam mereproduksi guru, sekaligus mempersempit peluang bagi calon lulusan S-1 kependidikan untuk menjadi guru. Hal ini tentunya harus ditindaklanjuti oleh pemerintah melalui kebijakan yang dapat menambah keunggulan lulusan S1 kependidikan agar tidak berdampak pula pada minat lulusan SMA untuk mengambil kuliah di jurusan kependidikan.

Berdasarkan hasil penelitian, diketahui bahwa $71 \%$ mahasiswa angkatan 2015 berkeinginan untuk mengikuti program PPG setelah mereka lulus S1. Alasan mereka tertarik mengikuti program PPG adalah supaya dapat sertifikasi saat mengabdi menjadi guru, ingin meningkatkan kompetensi, mendapatkan sertifikat pendidik sebagai syarat CPNS, memperdalam ilmu tentang mengajar, serta ingin diakui dalam kegiatan mengajar di sekolah. Terdapat $17 \%$ respondenyang tidak berminat untuk mengikuti program PPG setelah mereka lulus S1. Responden yang tidak berminat tersebut sudah merencanakan untuk melanjutkan kuliah ke jenjang S2 dan atau langsung bekerja. Sementara itu, 12\% mahasiswa angkatan 2015 menyatakan belum tertarik mengikuti program PPG setelah mereka lulus S1. Alasasan mahasiswa yang belum tertarik tersebut cukup bervariasi, yaitu ada yang ingin langsung bekerja, ada yang lantaran mereka merasa belum diwajibkan untuk mengikuti program PPG, dan adapula yang karena belum ingin menjadi guru. Gambar 4 menampilkan fenomena ketertarikan responden untuk mengikuti PPG.

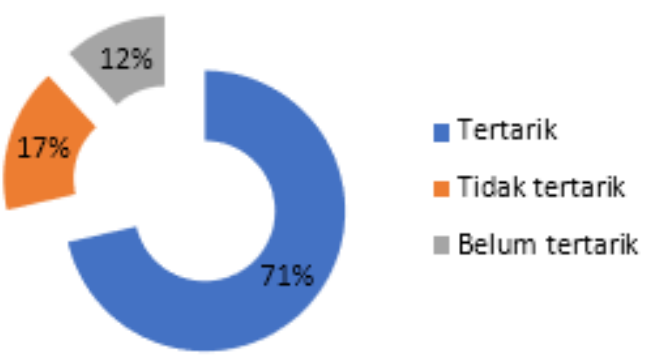

Gambar 4. Ketertarikan mengikuti PPG setelah lulus

Beberapa saran yang disampaikan oleh responden terkait pelaksanaan program $\mathrm{PPG}$ menunjukkan bahwa responden memiliki pesan terkait penyelenggaraan PPG. Beberapa saran yang terkait dengan penyelenggaraan antara lain kampus penyelenggara PPG dan kuota agar dapat diperbanyak,dosen pembimbing kualitasnya lebih bagus, pendaftaran dibuka setiap saat, dan proses pendaftaran agar dipermudah. Adapun saran terkiat dengan peserta program PPG, responden menyarankan agar diprioritaskan dari lulusan program studi kependidikan dan berasal dari daerah sesuai dengan daerah universitas yang didaftar. Terkait pendanaan, responden berharap biaya program PPG tidak mahal, saran ini muncul dikarenakan belum adanya informasi yang jelas pada mahasiswa terkait biaya. Responden hanya mendengar dari orang-orang sekitar tanpa mengetahui berapa nominal sesungguhnya dari biaya PPG. Responden juga merasa jika informasi terkait PPG perlu unuk disebarluaskan dengan lebih masif, hal ini karena responden merasa belum memiliki cukup referensi tepercaya terkait dengan PPG dan di kuliah belum banyak diberitahukan tentang hal ini.

Saran yang dikemukakan responden sejalan dengan penelitian yang dilakukan oleh Sumaryono \& Ismandiri (2015) yang menemukan bahwa sebagian mahasiswa yang menjadi responden mereka tidak tahu $(41,18 \%)$ ataupun ragu-ragudengan pengetahuan mereka $(50,20 \%)$ terkait program PPG.Demikian pula dengan hasil penelitian yang dilakukan oleh Kisrianto \&Iriani (2018) terhadap peserta program PPG. Responden dalam penitian tersebut mendapatkan informasi terkait PPG saat menempuh kuliahStarta 1 namun informasinya masih sangat umum (kurang terperinci) melalui diskusi sekilas dengan dosen dan sesama mahasiswa. Hal ini seharusnya bisa 
menjadi masukan bagi pemerintah untuk lebih giat menyebarkan informasi terkait PPG kepada mahasiswa. Selain itu, dari analisis yang dilakukan oleh Disas (2017) mengungkapkan bahwa beberapa kekurangan dari program PPG ini antara lain biaya yang mahal dalam menempuh PPG, serta sosialisasi yang belum maksimal.

\section{Simpulan, Saran, dan Rekomendasi}

Hampir seluruh mahasiswa memeliki pengetahuan terkait dengan PPG. Meskipun demikian, sumber pengetahuan ini masih beragam dan diperoleh ketika sudah kuliah. Sumber ini yang dianggap mahasiswa masih kurang ada kejelasan ketika di perkuliahan. Pengetahuan mahasiswa angkatan 2015 terkait sasaran, manfaat, dan pelaksanaan program PPG bervariasi. Ketertarikan mahasiswa mengikuti program PPG lebih banyak dibandingkan dengan yang tidak. Penelitian ini masih belum menggali tentang persepsi mahasiswa yang berkaitan dengan motif mengikuti program PPG. Hasil penelitian ini dapat menjadi bagian saran bagi pemerintah dan penyelenggara terkait dengan program ini terutama pada kemudahan akses informasi dan penyelenggaraan PPG bagi mahasiswa.

\section{Daftar Pustaka}

Disas, E., P. (2017). Analisis kebijakan pendidikan mengenai pengembangan dan peningkatan profesi guru. Jurnal Penelitian Pendidikan, 17(2), 158-166.

Kisrianto, A., G. \& Iriani, C. (2018). Persepsi mahasiswa program pendidikan profesi guru (PPG) pendidikan sejarah terhadap program PPG. Jurnal Pendidikan Sejarah, 7(1), 66-83.

Margi, I., K., \& Atmadja, N., B. (2013). Program pendidikan profesi guru prajabatan dalam perspektif darwinisme sosial. Jurnal Pendidikan dan Pengajaran, 46(1), 87-95.

Ningrum, E. (2012). Membangun sinergi pendidikan akademik (S1) dan pendidikan profesi guru (PPG). Jurnal Pendidikan Geografi, 12(2), 49-55.

Sumaryono, I. \& Ismandiri, D. (2015). Persepsi mahasiswa kependidikan fakultas ekonomi universitas negeri Yogyakarta terhadap pendidikan profesi guru (PPG). Pelita, 10(1).

Yustina \& Wansyafii. (2016). Kompetensi pengetahuan pedagogi konten melalui workshop pada peserta PPG SM-3T pendidikan biologi-UR. Proceeding Biologi Education Conference, 13(1), 468474.

Yusutria. (2017). Profesionalitas guru dalam meningkatkan kualitas sumberdaya manusia. Curricila, 2(1),38-46

Menteri Pendidikan dan Kebudayaan Republik Indonesia. (2013). Peraturan Menteri Pendidikan Dan Kebudayaan Republik Indonesia Nomor 87 Tahun 2013 Tentang Program Pendidikan Profesi Guru Prajabatan. Jakarta: Kementerian Pendidikan dan Kebudayaan. 